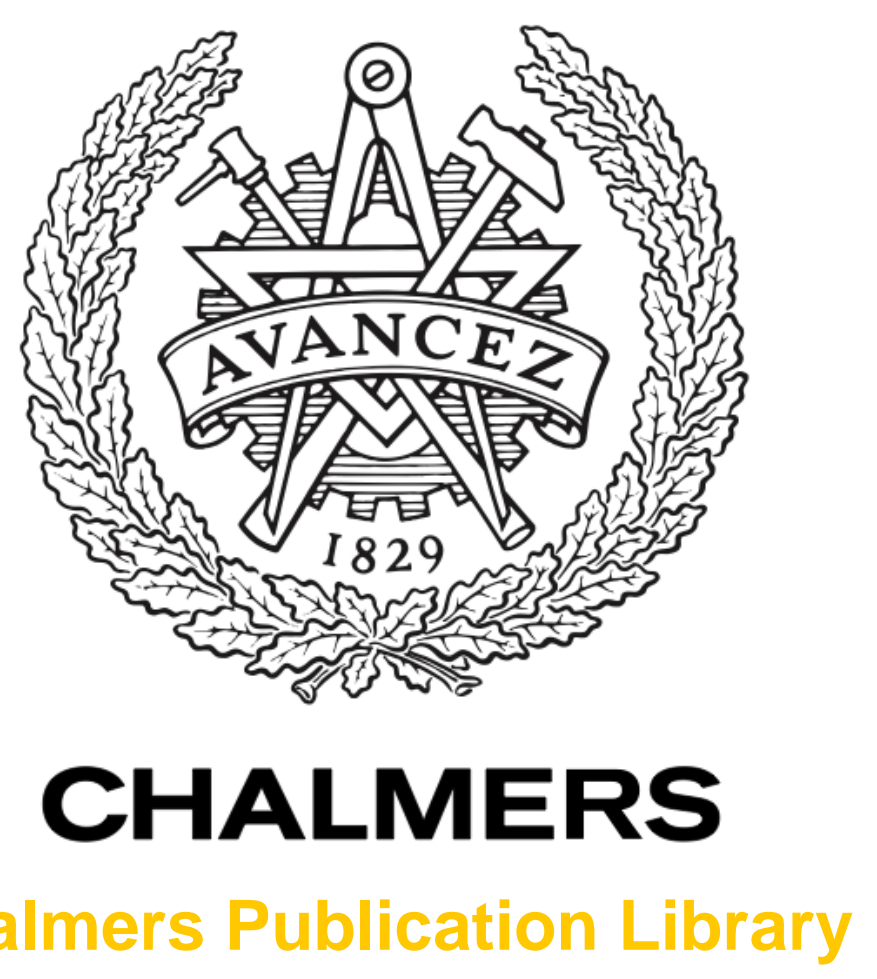

Challmers Publication Library

\title{
Crack Widths Close to the Reinforcement
}

This document has been downloaded from Chalmers Publication Library (CPL). It is the author's version of a work that was accepted for publication in:

\section{IABSE Symposium Improving Infrastructure Worldwide}

Citation for the published paper:

Tammo, K. ; Thelandersson, S. ; Lundgren, K. (2007) "Crack Widths Close to the

Reinforcement". IABSE Symposium Improving Infrastructure Worldwide

Downloaded from: http://publications.lib.chalmers.se/publication/54301

Notice: Changes introduced as a result of publishing processes such as copy-editing and formatting may not be reflected in this document. For a definitive version of this work, please refer to the published source. Please note that access to the published version might require a subscription. 


\section{Crack Widths Close to the Reinforcement}

\author{
Kristian Tammo \\ Civil Engineer \\ Lunds Tekniska Högskola \\ Lund University \\ Lund, Sweden \\ Kristian.Tammo@kstr.lth.se
}

Kristian Tammo, born 1978, received his civil engineering degree from the Univ. of Lund 2003.

\author{
Karin Lundgren \\ Associate Professor \\ Chalmers University of \\ Technology \\ Gothenburg, Sweden \\ Karin.Lundgren@chalmers.se
}

Karin Lundgren is associate professor in Concrete Strucutures at Chalmers University of Technology.

\author{
Sven Thelandersson \\ Professor \\ Lunds Tekniska Högskola \\ Lund University \\ Lund, Sweden \\ Sven.Thelandersson@kstr.lth.se
}

Sven Thelandersson, born 1944, is professor in Structural Engineering at Lund University.

\section{Summary}

Currently used design methods predict that the crack widths at the concrete surface increase significantly with concrete cover. Requirements concerning limitation of crack widths therefore makes it difficult to use large concrete covers, which otherwise is desirable to reduce the corrosion of reinforcement. For this reason it would be more relevant to limit the crack width in the vicinity of the reinforcement bars. In this paper experimental studies to investigate how concrete cover affects the crack width at the reinforcement level are presented. Axially loaded concrete prisms with central reinforcement bars and beams loaded with bending moment are tested with a method making it possible to measure crack widths near the reinforcement. Concrete cover, bar diameter and concrete quality are varied. The test results show that the crack width close to the bar is only to a limited extent affected by concrete cover, bar diameter and concrete quality. Three-dimensional, non-linear FE-calculations are also performed to understand the mechanisms determining the properties of a crack.

Keywords: Beam, concrete, corrosion, crack width, durability, FEM.

\section{Introduction}

One of the most important factors governing durability of concrete structures is reinforcement corrosion, and to prevent degradation associated with it, it is desirable to use large concrete covers. As long as the concrete close to the reinforcement bars is unaffected by carbonation and no chlorides reach the steel the risk of corrosion is very low. The time of carbonation and chlorides to reach the reinforcement is proportional to the square of the concrete cover [1]. A doubling of the cover therefore increases the time until corrosion starts with a factor of four.

Structural codes usually require that crack widths at the concrete surface shall be limited, among other things to prevent corrosion of reinforcement. If the concrete cover is increased, some currently used design methods, such as that given in Eurocode 2 [2], will predict that the crack widths at the concrete surface increase significantly. Therefore, requirements concerning limitation of crack widths make it difficult to use large concrete covers, unless the total amount of crack reinforcement is increased significantly.

Current design practice for crack control only considers crack widths at the concrete surface. With respect to the risk of corrosion, the crack width in the vicinity of the reinforcement bars should be more relevant. Test results by a number of researchers [3]-[7] show that the surface crack widths are of the order twice the crack width close to the bar surface for normal thicknesses of concrete 
cover. These circumstances point to the hypothesis that a more rational approach to crack control in concrete structures could allow the designers to use larger concrete cover, without unwanted effects concerning corrosion initiated via cracks or large amounts of crack reinforcement.

The present paper presents the results of an experimental investigation of crack widths near the reinforcement as influenced by steel stress, concrete cover, bar diameter and concrete quality for axially loaded concrete prisms and beams loaded in bending. The mechanism of cracking behaviour is also evaluated with the finite element method, where the cracking behaviour will be simulated and compared with experimental observations.

\section{Experimental studies}

\subsection{Axially loaded concrete prisms}

The concrete prisms had a central reinforcing bar, as shown in Fig. 1. Two diameters $\phi$ of the reinforcement bar, $12 \mathrm{~mm}$ and $16 \mathrm{~mm}$ and three different concrete covers $c, 30 \mathrm{~mm}, 50 \mathrm{~mm}$ and 70 $\mathrm{mm}$, were used. Prisms with a length of $500 \mathrm{~mm}$ were used for specimens with concrete covers of $30 \mathrm{~mm}$ and $50 \mathrm{~mm}$, while a length of 500 or $1000 \mathrm{~mm}$ was used for concrete cover of $70 \mathrm{~mm}$. Tension is applied directly to the reinforcing bar under displacement control with a movement of $0.42 \mathrm{~mm} / \mathrm{min}$, and slip of the bar is measured relative to the concrete surface at the end of the prism, as shown in Fig. 2. The concrete prisms are loaded until the steel stress reaches $400 \mathrm{MPa}$. The axially loaded concrete prisms are intended to represent the tension zone of a reinforced beam under bending. The number of tested specimens is presented in Table 1.

Table 1 Test program.

\begin{tabular}{|ccccccccc|}
\hline Series & $\begin{array}{c}\text { Side of } \\
\text { prism } \\
\mathrm{mm}\end{array}$ & Cover & Length & $\begin{array}{c}\text { Concrete } \\
\text { quality }\end{array}$ & $\begin{array}{c}\text { Bar } \\
\text { diameter } \phi \\
\mathrm{mm}\end{array}$ & $\begin{array}{c}\text { Distance } a \\
\mathrm{~mm}\end{array}$ & $\begin{array}{c}\text { No. of } \\
\text { specimens }\end{array}$ & $\begin{array}{c}\text { No. of slip } \\
\text { readings } \\
w_{a} / w_{\text {surf }}\end{array}$ \\
\hline A1.50.16 & 76 & 30 & 500 & C40/50 & 16 & 4.5 & 4 & $6 / 2$ \\
A2.50.16 & 76 & 30 & 500 & C40/50 & 16 & 11 & 4 & $8 / 2$ \\
B1.50.16 & 116 & 50 & 500 & C40/50 & 16 & 4.5 & 4 & $6 / 2$ \\
B2.50.16 & 116 & 50 & 500 & C40/50 & 16 & 11 & 4 & $8 / 2$ \\
C1.50.16 & 156 & 70 & 500 & C40/50 & 16 & 4.5 & 2 & $4 / 2$ \\
C2.50.16 & 156 & 70 & 1000 & C40/50 & 16 & 11 & 4 & $8 / 2$ \\
\hline A.25.12 & 72 & 30 & 500 & C20/25 & 12 & 11 & 4 & $8 / 8$ \\
B.25.12 & 112 & 50 & 500 & C20/25 & 12 & 11 & 4 & $8 / 8$ \\
C. 25.12 & 152 & 70 & 1000 & C20/25 & 12 & 11 & 4 & $8 / 8$ \\
\hline A.25.16 & 72 & 30 & 500 & C20/25 & 16 & 11 & 4 & $8 / 8$ \\
B.25.16 & 112 & 50 & 500 & C20/25 & 16 & 11 & 4 & $8 / 8$ \\
C. 25.16 & 152 & 70 & 1000 & C20/25 & 16 & 11 & 4 & $8 / 8$ \\
\hline A.50.12 & 72 & 30 & 500 & C40/50 & 12 & 11 & 4 & $8 / 8$ \\
B.50.12 & 112 & 50 & 500 & C40/50 & 12 & 11 & 4 & $8 / 8$ \\
C.50.12 & 152 & 70 & 1000 & C40/50 & 12 & 11 & 4 & $8 / 8$ \\
\hline
\end{tabular}

The reinforcement is of quality B500B with characteristic yield strength of $500 \mathrm{MPa}$. All reinforcement used in the tests came from the same shipment. The concrete qualities used in the tests are $\mathrm{C} 20 / 25$ and $\mathrm{C} 40 / 50$.

Slip of the bar at the specimen end is measured with two LVDT-gauges (accuracy of $0.001 \mathrm{~mm}$ ) to determine the displacement of a point on the bar $70 \mathrm{~mm}$ from the concrete end surface relative the 
concrete surface at a distance $a$ from the bar surface, as shown in Fig. 2. A metal tube with knife edges glued to the concrete end surface was used, so that the position $a$ could be determined with high precision. The average reading of the two LVDT-gauges is corrected for elongation of the bar over the $70 \mathrm{~mm}$ length, based on the applied load and a measured value of EA for the bars. The measured slip relative different positions on the end surface is intended to represent the behaviour in one of the faces of a preexisting crack. By this approach the measured slip can be considered as half the crack width at a defined distance $a$ from the reinforcing bar surface. In this study the distance $a$ is $4.5 \mathrm{~mm}$ and $11 \mathrm{~mm}$. The crack width $4.5 \mathrm{~mm}$ and $11 \mathrm{~mm}$ from the reinforcement bar is therefore calculated as twice the measured slip.

Additional LVDT-gauges were also mounted to measure the slip relative to the outer concrete surface at the specimen ends, as shown in Fig. 2. The average readings from these gauges are used in a similar way to determine crack width at the concrete surface.

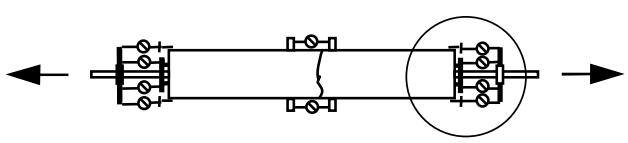

Fig. 1 Experimental setup.

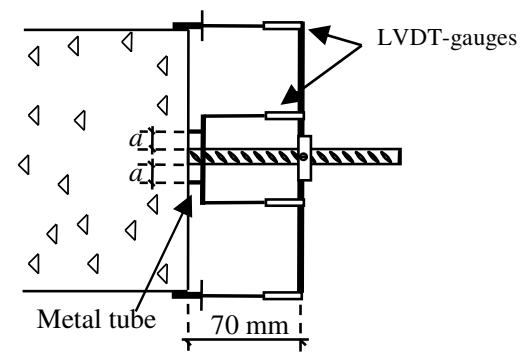

Fig. 2 Blow up of arrangement of the measuring device at one end of the specimen

\subsection{Beams loaded in bending}

Two different beams were tested and compared with each other. The beams had a fixed effective depth of $150 \mathrm{~mm}$ but different concrete covers $c$ of $30 \mathrm{~mm}$ and $50 \mathrm{~mm}$. The dimensions of the beams are presented in Fig. 3. A continuous reinforcement bar with diameter $\varnothing 16 \mathrm{~mm}$ and the quality B500B was placed symmetrically and is free in the middle of the beam, see Fig. 3. The slip of the bar was measured relative to the free surfaces by the method described for the axially loaded prisms, see section 2.1. The beams were loaded as in Fig. 3 until the steel stress was $350 \mathrm{MPa}$. Strain gauges were placed on the reinforcement so that the steel stress and strain could be determined precisely. The concrete quality used for the beams is C40/50. Totally 10 beams for each concrete cover have been tested.

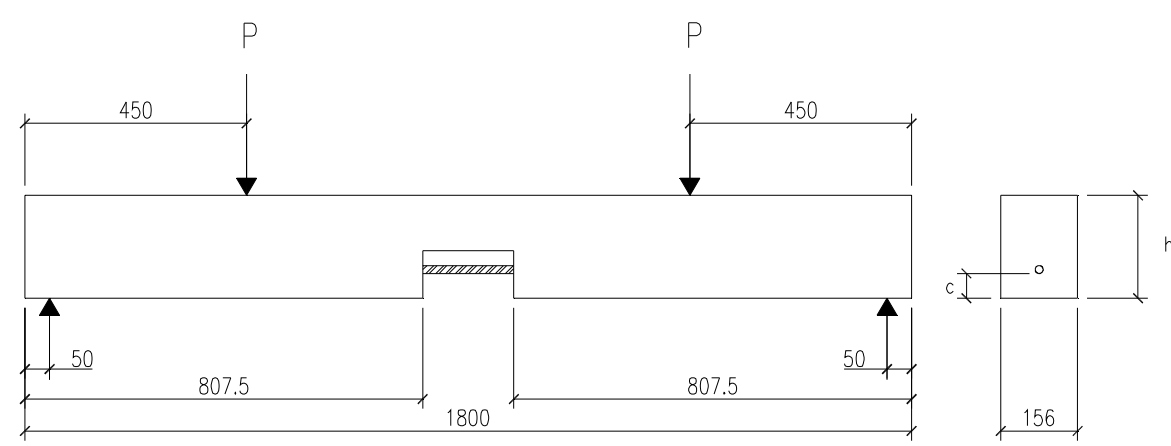

Fig. 3 Dimensions of the beams and positions for the loads $(P)$. The depths $h$ of the beams were $188 \mathrm{~mm}$ or $208 \mathrm{~mm}$ and the concrete cover $\mathrm{c}$ is $30 \mathrm{~mm}$ or $50 \mathrm{~mm}$. 


\section{Finite element analyses}

To increase the understanding of the crack mechanisms a finite element model is used. Non-linear fracture mechanics is used for the concrete material, and a model by Lundgren [8] is used to model the bond between steel and concrete. Concrete and reinforcement are modelled with solid elements and the connection between concrete and reinforcement is modelled with special interface elements. These elements describe the traction $\mathbf{t}$ and the relative displacement $\mathbf{u}$ in the interface and have, initially, a thickness of zero. The variables in these interface elements are $t_{n}, t_{t}, u_{n}$ and $u_{t}$, see Fig. 4 .

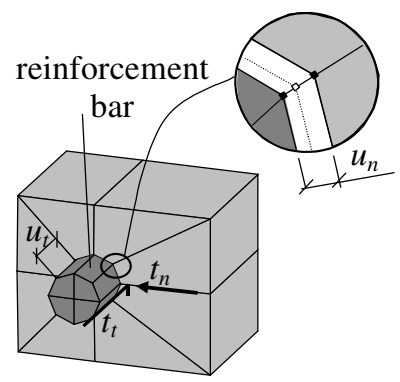

$$
\begin{aligned}
& t_{n}=\text { normal stress } \\
& t_{t}=\text { bond stress } \\
& u_{t}=\text { slip } \\
& u_{n}=\text { relative normal displacement in the layer }
\end{aligned}
$$

Fig. 4 The connection between concrete and reinforcement is modelled with special interface elements. From Lundgren [8].

The model for the interface is a frictional model based on elasto-plastic theory and describes the relations between stresses and displacements. The equations for this model are:

$\boldsymbol{t}=\left[\begin{array}{l}t_{n} \\ t_{t}\end{array}\right]=\left[\begin{array}{cc}D_{11} & 0 \\ 0 & D_{22}\end{array}\right]\left[\begin{array}{l}u_{n} \\ u_{t}\end{array}\right]$

The yield line describing friction, $F_{1}$, can be written as:

$$
F_{1}=\left|t_{t}\right|+\mu\left(t_{n}-f_{a}\right)=0
$$

where $\mu$ is the coefficient of friction, and $f_{a}$ is the adhesion.

For the yield line describing the friction, $F_{1}$, a non-associated flow rule is assumed, where the plastic part of the displacement, $d \mathbf{u}^{\mathbf{p}}$, is described by:

$$
d \mathbf{u}^{\mathbf{p}}=d \lambda \frac{\partial G}{\partial \mathbf{t}}, \quad G=\frac{\left|u_{t}\right|}{u_{t}} t_{t}+\eta t_{n}=0
$$

where $d \lambda$ is the incremental plastic multiplier and $\eta$ is dilation parameter.

For the hardening rule of the model, a hardening parameter $\kappa$ is established. It is defined as:

$$
d \kappa=\sqrt{d u_{n}^{p^{2}}+d u_{t}^{p^{2}}}
$$

The input values are equal as in Lundgren [8] except that the adhesion between steel and concrete is included in this model. The adhesion is considered to vary with the hardening parameter $\kappa$ as:

Table 2 Adhesion.

\begin{tabular}{|cc|}
\hline$\kappa(\mathrm{m})$ & Adhesion $(\mathrm{MPa})$ \\
\hline 0 & 2 \\
$6.41 \cdot 10^{-4}$ & 0,001 \\
$\geq 1.07 \cdot 10^{-3}$ & 0 \\
\hline
\end{tabular}


The finite element study is limited to only concern the two largest specimens with concrete cover $50 \mathrm{~mm}$ and $70 \mathrm{~mm}$, with the bar diameter $\varnothing 16 \mathrm{~mm}$ and the concrete quality C40/50 from the experimental study of the axially loaded concrete prisms.

The structure of the elements in the finite element mesh is simplified to a cylinder with circular cross section by using an axisymmetric model. The diameter of the circular cross section is equal to the sides of the square cross section tested in the experimental study, as shown in Fig. 5 and the length of the cylinder is $500 \mathrm{~mm}$ for all cases. Because of the symmetry the length of the specimen is halved to the length $250 \mathrm{~mm}$ in the finite element model, as shown in Fig. 6.
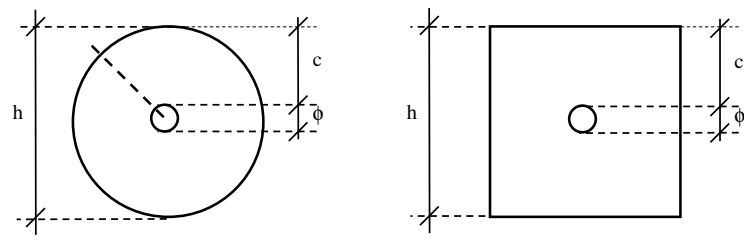

Fig. 5 The quadratic cross section of the test specimens is simplified to a circular cross section in the finite element model.

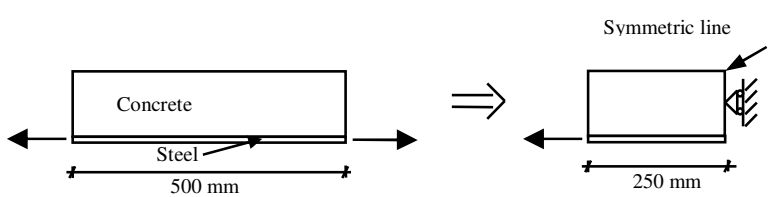

Fig. 6 Because of the symmetric effects the length of the specimen is halved in the model.

The method of finding the slip, which is interpreted as half the crack width, in the finite element model is similar as for the real test specimens. The distance $a$ from the bar surface is in this case 5 and $10 \mathrm{~mm}$ instead of 4.5 and $11 \mathrm{~mm}$.

Because of instable cracking process some calculations do not converge when the cracks propagate. The analysis results for the specimen with concrete cover $50 \mathrm{~mm}$ are considered as reliable until the steel stress is $400 \mathrm{MPa}$ and for the specimen with concrete cover $70 \mathrm{~mm}$ until the steel stress is $300 \mathrm{MPa}$.

\section{Results}

In Figs. 7-10 regression curves representing the average response of the axially loaded concrete prisms are presented for concrete covers $c$ of $30 \mathrm{~mm}, 50 \mathrm{~mm}$ and $70 \mathrm{~mm}$. Concrete quality is $\mathrm{C} 20 / 25$ or $\mathrm{C} 40 / 50$ and bar diameter $\phi$ is 12 and $16 \mathrm{~mm}$. The $\mathrm{R}^{2}$-values for the regression curves are in all cases over 0.6 which is acceptable as a lower limit for reliable results.

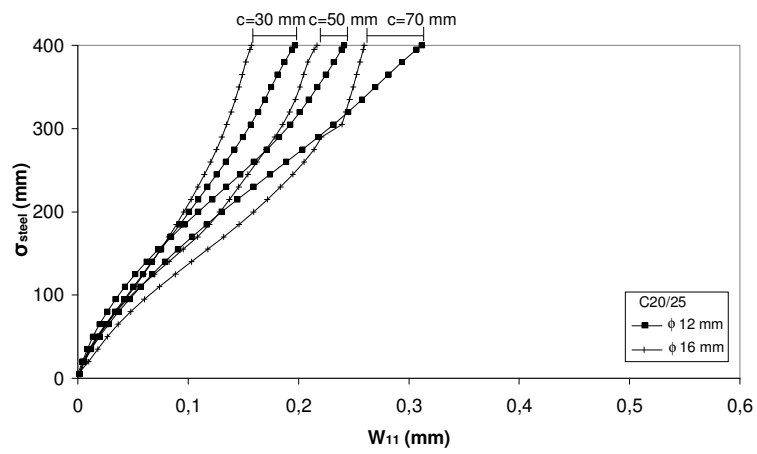

Fig. 7 Regression curves for measured crack widths $11 \mathrm{~mm}$ from the reinforcement bar. Concrete quality is C20/25.

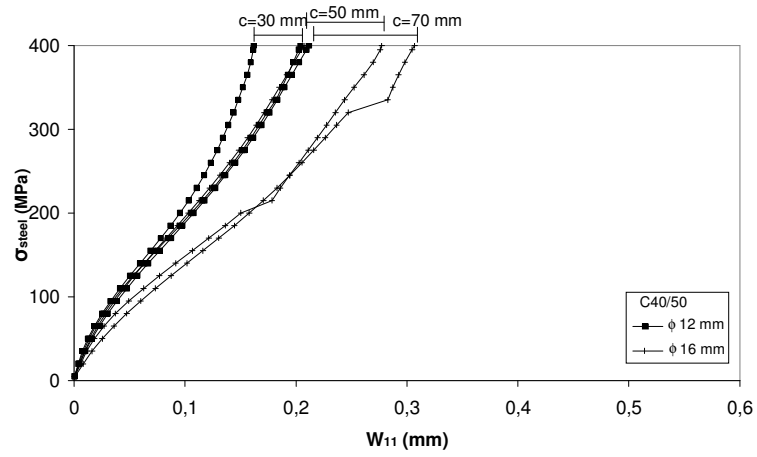

Fig. 8 Regression curves for measured crack width $11 \mathrm{~mm}$ from the reinforcement bar. The concrete quality is C40/50. 


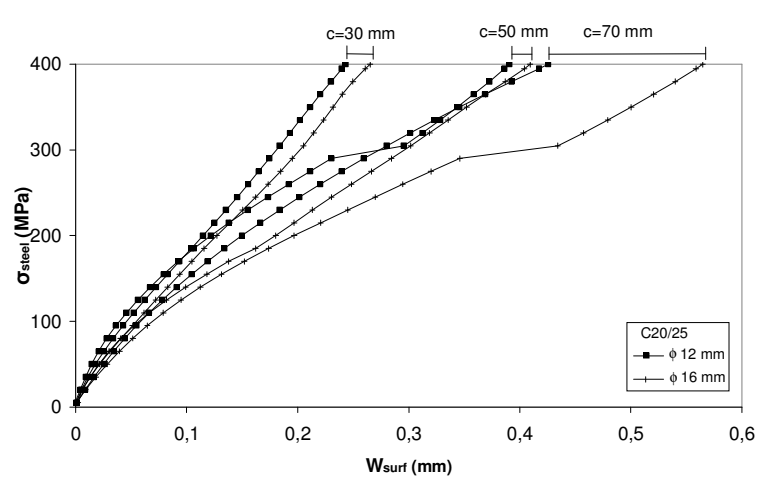

Fig. 9 Regression curves for measured crack widths at the concrete surface. The concrete quality is C20/25.

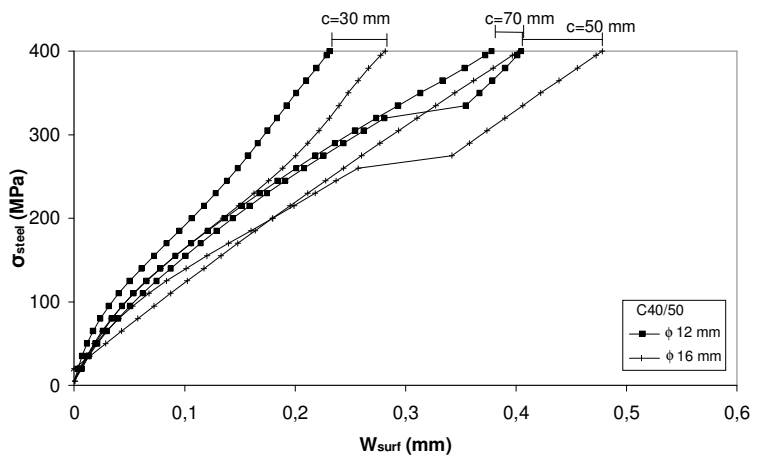

Fig. 10 Regression curves for measured crack widths at the concrete surface. The concrete quality is $C 40 / 50$.

The crack widths for the beams loaded in bending are presented in Fig. 11. The graphs in the figure are the mean values of all measurements for beams with concrete cover $c$ of $30 \mathrm{~mm}$ and $50 \mathrm{~mm}$. Concrete quality is C40/50 and bar diameter $\phi$ is $16 \mathrm{~mm}$.

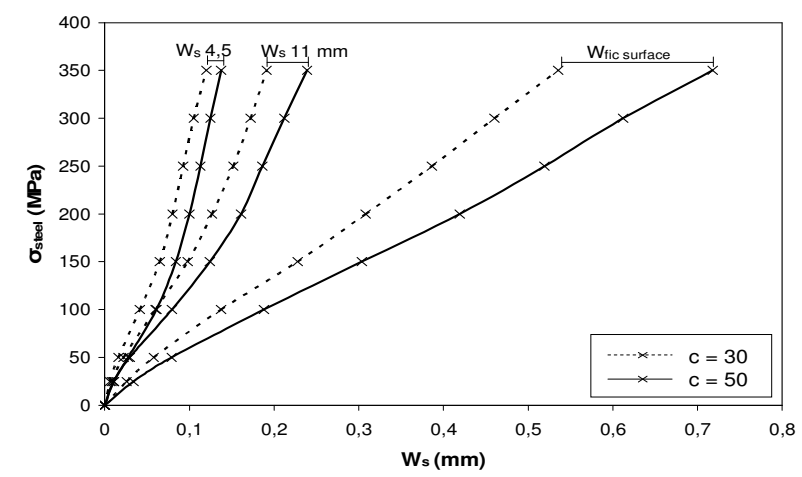

Fig. 11 Mean values of the crack widths $4.5 \mathrm{~mm}$ (Ws 4.5) and $11 \mathrm{~mm}$ (Ws 11) from the reinforcement and at the concrete surface (Wfic surface) for beams loaded in bending .

The results of the crack widths from the finite element analysis at different distances from the bar surface are compared with the results from the tested axially loaded concrete prisms in Fig. 12 and Fig. 13. The concrete cover $c$ is $50 \mathrm{~mm}$ and $70 \mathrm{~mm}$. The bar diameter is $\emptyset 16 \mathrm{~mm}$ and the concrete quality C40/50. The graphs from the finite element analysis in Fig. 13 are only presented for results considered as reliable.

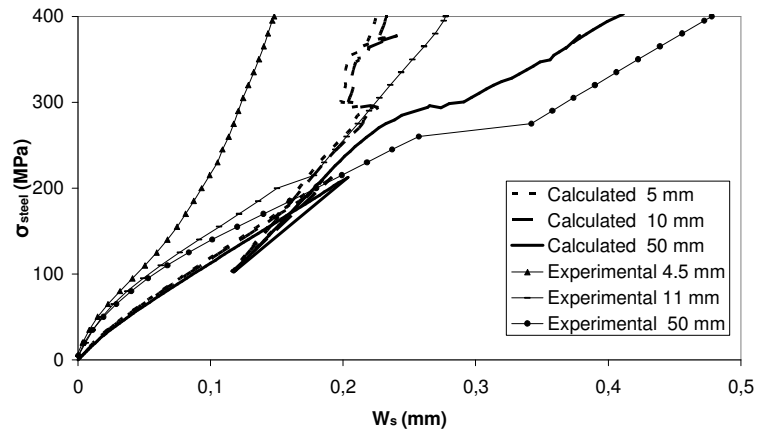

Fig. 12 Crack widths at different distances from the reinforcement bar for the specimen with concrete cover $50 \mathrm{~mm}$.

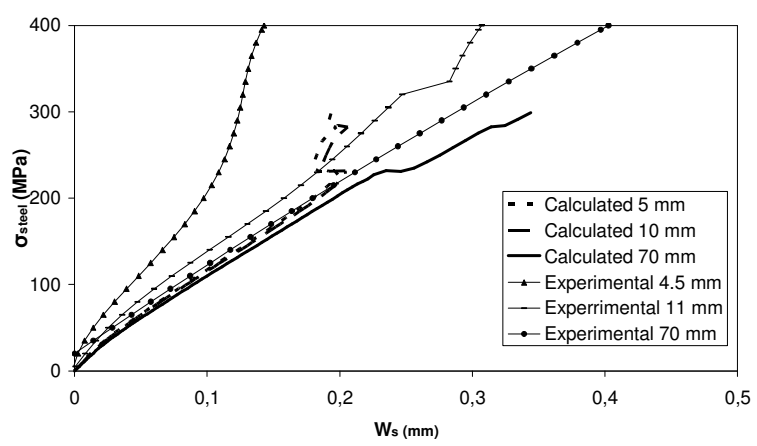

Fig. 13 Crack widths at different distances from the reinforcement bar for the specimen with concrete cover $70 \mathrm{~mm}$. 
For high steel stresses cone formed concrete pieces around the bar are separated from the rest of the concrete in the finite element analysis and follows the elongation of the bar, see Fig.14 for the specimen with the cover $50 \mathrm{~mm}$. This behaviour is similar for the larger specimen with the cover $70 \mathrm{~mm}$.

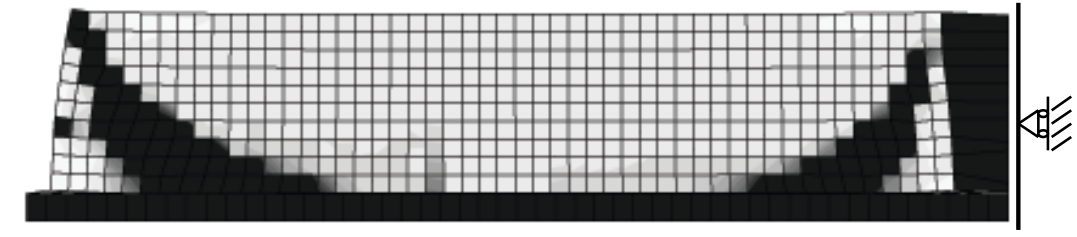

Fig. 14 Finite element for axially loaded specimen with concrete cover $50 \mathrm{~mm}$ and steel stress $400 \mathrm{MPa}$. A new crack is formed on the right side of the mesh, which represents the middle of the specimen. Dark areas represent cracked concrete, with principal tensile strains larger than 0.001 .

\section{Analysis and Discussion}

The tests performed in the present paper show that the crack width varies significantly from the bar to the concrete surface, as shown in Figs. 7-13. It is also clear that the crack width closest to the reinforcement is much less influenced by the cover thickness than the crack width at the concrete surface. The difference of crack width close to the bar and at the concrete surface is even more obvious for the beams loaded in bending, see Fig. 11. The crack width $4.5 \mathrm{~mm}$ from the reinforcement bar seems to be almost unaffected by the cover for the beams, as shown in Fig. 11. The crack widths at the concrete surface in Figs. 9-13 that are measured with the methods described in section 2, seem to be larger than crack widths measured with standard methods on continuous beams. The reason for this can be that the damage in the bond zone becomes more significant in a pre-existing crack, where the bond zone is stressed from the outset.

The bar diameter has a moderate effect on both the crack width $11 \mathrm{~mm}$ from the reinforcement bar and at the concrete surface, and this effect increases with steel stress. The larger bar diameter of $16 \mathrm{~mm}$ gives in most cases larger crack widths than the smaller bar diameter of $12 \mathrm{~mm}$ at the same steel stress as observed in Fig. 8-Fig. 10. However, in Fig. 7, for concrete C20/25 the opposite effect is found, so that the crack width $11 \mathrm{~mm}$ from the reinforcement bar for high steel stresses is slightly larger for the smaller bar. In cases where there is a significant effect of bar diameter, see e.g. Fig. 9, this can be attributed to the fact that cracks were formed at mid length of the specimen for the larger bar diameter but not for tests with $12 \mathrm{~mm}$ bars. However, the effect of the reinforcement bar diameter can be considered as small.

The quality of the concrete has no significant effect on the observed crack widths, neither close to the bar nor at the concrete surface. This is in agreement with current design formulae, where concrete strength has very little influence.

The finite element simulations exhibit similar mechanisms of crack propagation as observed in the tests. The calculated crack widths at the concrete surface agree reasonably well with the measured values. However, the calculated crack widths close to the bar were for low steel stresses larger than the measured crack widths, see Fig. 7 and Fig. 8. The reason for this is that the detailed non-linear damage processes of the bond zone near the crack is not described in detail by the finite element analysis. The measured response $4.5 \mathrm{~mm}$ from the bar deviates already at low stresses from the finite element analysis. The same is valid for the crack width $11 \mathrm{~mm}$ from the bar but at higher steel stresses. However, the results of the calculations can to some extent verify the statement that the 
crack width close the reinforcement bar is almost unaffected of the size of the concrete cover. As an example: If the steel stress is $300 \mathrm{MPa}$ the calculated crack width is $0.204 \mathrm{~mm} 10 \mathrm{~mm}$ from the bar surface and $0.291 \mathrm{~mm}$ at the concrete surface for the specimen with concrete cover $50 \mathrm{~mm}$. For the specimen with concrete cover $70 \mathrm{~mm}$ the corresponding crack widths are $0.201 \mathrm{~mm}$ and $0.344 \mathrm{~mm}$.

In Fig. 12 and Fig. 13 a cone formed concrete piece is formed in the specimens at an approximate steel stress of $300 \mathrm{MPa}$. This is shown as an immediate increase of the difference of the crack width closest to the reinforcement and the crack width at the concrete surface. The cone formed concrete piece is visible in Fig. 14 and has also been verified by colouring the cracked zone behind the cone with phenolftalein in some of the tested concrete prisms described in table 1.

\section{Conclusions}

- Crack widths in reinforced concrete increase with distance from the reinforcement bars towards the free surface.

- Crack widths near the bar are much less affected by changes in concrete cover and bar diameter than the crack width at the free concrete surface.

- Nonlinear mechanisms that affect the crack width close the reinforcement bar are to some extent possible to describe with the finite element method

- Results of finite element calculations verify the statement that for the crack widths close to the reinforcement bar the concrete cover is not very important

\section{References}

[1] TUTTI K., "Corrosion of steel in concrete,” CBI Research fo 4.82, Stockholm, 1982.

[2] Eurocode 2, prEN 1992-1-1., Design of concrete structures - Part 1-1: General Rules and Rules for Building, CEN, 2003.

[3] WATSTEIN D., and MATHEY, R., "Width of cracks in concrete at the surface of reinforcing steel evaluated by means of tensile bond specimens," J. Am. Concr. Inst., 56, No. 7, July 1959, pp. 47-56.

[4] HUSAIN S. I., and FERGUSON, P. M., "Flexural Cracks Widths at the Bars in Reinforced Concrete beams," Research Report No. 102.1F., Center for Highway Research, The University of Texas at Austin, June 1968.

[5] ILLSTON J. M., and STEVENS R.F., "Long term cracking in reinforced concrete beams," Proceedings of the Institution of Civil Engineers, Part II, Research and Theory, 53, 1972, pp. 445459.

[6] YANNOPOULUS P. J., "Variation of concrete crack widths through the concrete cover to reinforcement," Magazine of concrete research, No. 147, 41, 1989, pp. 63-68.

[7] TAMMO K., and THELANDERSSON S., "Crack opening near reinforcement bars in concrete structures" Structural Concrete, Journal of the fib, 2006, pp 137-142.

[8] LUNDGREN K., "Bond between ribbed bars and concrete. Part 1: Modified model," Magazine of concrete research, No. 7, 57, 2005, pp. 371-382. 